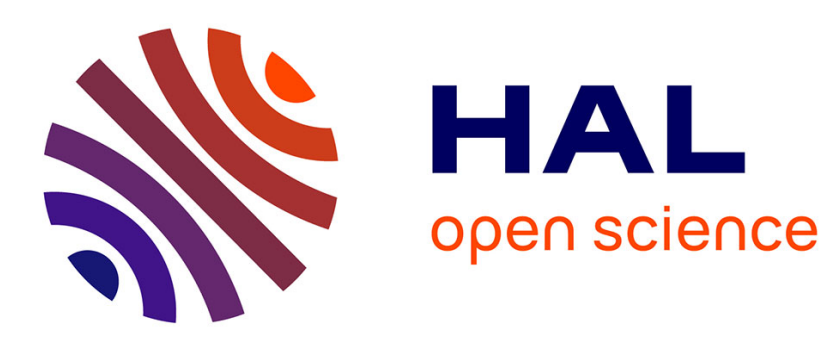

\title{
Influence of silica fillers on the ageing by gamma radiation of EDPM nanocomposites
}

Emilie Planes, Laurent Chazeau, Gérard Vigier, Thomas Stuhldreier

\section{To cite this version:}

Emilie Planes, Laurent Chazeau, Gérard Vigier, Thomas Stuhldreier. Influence of silica fillers on the ageing by gamma radiation of EDPM nanocomposites. Composites Science and Technology, 2007, 10.1016/j.compscitech.2010.05.010 . hal-00485520

\section{HAL Id: hal-00485520 \\ https://hal.science/hal-00485520}

Submitted on 21 May 2010

HAL is a multi-disciplinary open access archive for the deposit and dissemination of scientific research documents, whether they are published or not. The documents may come from teaching and research institutions in France or abroad, or from public or private research centers.
L'archive ouverte pluridisciplinaire HAL, est destinée au dépôt et à la diffusion de documents scientifiques de niveau recherche, publiés ou non, émanant des établissements d'enseignement et de recherche français ou étrangers, des laboratoires publics ou privés. 


\section{Accepted Manuscript}

Influence of silica fillers on the ageing by gamma radiation of EDPM nanocomposites

Emilie Planes, Laurent Chazeau, Gérard Vigier, Thomas Stuhldreier

PII: S0266-3538(10)00184-3

DOI: 10.1016/j.compscitech.2010.05.010

Reference: CSTE 4715

To appear in: Composites Science and Technology

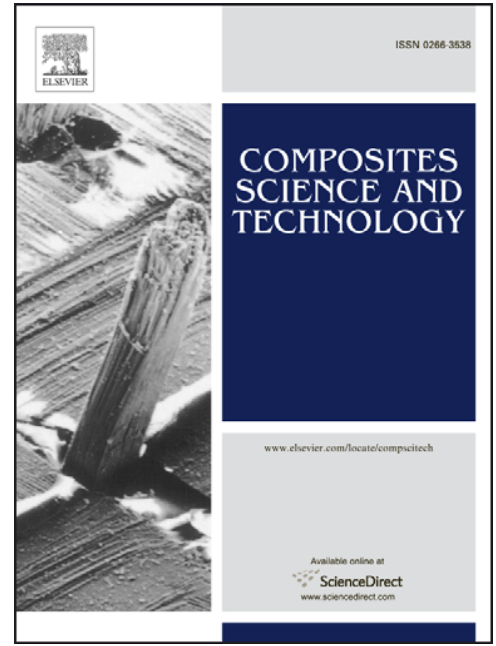

Received Date: $\quad 9$ February 2010

Revised Date: $\quad 29$ April 2010

Accepted Date: $\quad 5$ May 2010

Please cite this article as: Planes, E., Chazeau, L., Vigier, G., Stuhldreier, T., Influence of silica fillers on the ageing by gamma radiation of EDPM nanocomposites, Composites Science and Technology (2010), doi: 10.1016/ j.compscitech.2010.05.010

This is a PDF file of an unedited manuscript that has been accepted for publication. As a service to our customers we are providing this early version of the manuscript. The manuscript will undergo copyediting, typesetting, and review of the resulting proof before it is published in its final form. Please note that during the production process errors may be discovered which could affect the content, and all legal disclaimers that apply to the journal pertain. 


\title{
Influence of silica fillers on the ageing by gamma radiation of EDPM nanocomposites
}

Emilie PLANES $^{\mathrm{a} b}$, Laurent CHAZEAU ${ }^{\mathrm{a} i}$, Gérard VIGIER $^{\mathrm{a}}$, Thomas STUHLDREIER ${ }^{\mathrm{b}}$

${ }^{a}$ MATEIS, Bâtiment Blaise Pascal, INSA-Lyon, 20 Avenue Albert Einstein, F-69621 Villeurbanne Cedex, France

b NEXANS RESEARCH CENTER, 170 Avenue Jean Jaurès, F-69353 Lyon Cedex 07, France

\begin{abstract}
:
This study evidences that the presence of silica fillers as well as their surface treatment influences the impact of gamma irradiation on the mechanical properties of the filled materials. It influences it both chemically, by a modification of the kinetics of the degradation reactions, and physically, through the complex modification of the filler-filler and fillermatrix interactions involved in the mechanical properties of the filler network.
\end{abstract}

Keywords:

Nanocomposites, mechanical properties, environmental degradation

${ }^{\mathrm{i}}$ Corresponding author: Tel : +33 472436130 ; fax : +33 472438528.

E-mail address : laurent.chazeau@insa-lyon.fr (L. Chazeau) 


\section{Introduction}

Some applications of filled elastomer can involve ageing by gamma irradiation. For instance, the elastomers used as cable insulation in nuclear power plants are submitted to irradiation during their lifetime. Several studies have been devoted to the understanding of the consequences of ageing by gamma radiation on the mechanical properties of unfilled elastomers such as Ethylene-Propylene Diene Monomer (EPDM) or Poly DiMethyl Siloxane (PDMS) $[1,2,3,4,5,6]$. Thus, a scheme of the chemical reactions involved in the degradation process of EPDM under gamma radiation has been established from a fine analysis of the degradation products [3,4]. From a microstructural point of view, these reactions can be, within more or less important simplification, related to scissions and/or crosslinkings of the polymer chains $[5,6]$

However in most applications, elastomers are formulated with fillers, which are in many cases nanoscopic. For instance, incorporation of nanoscopic silica fillers in elastomers is well known to improve their mechanical properties [7]. However, the use of such fillers, with a very large interface area, can also influence the degradation mechanisms. They can modify the polymer degradation by trapping radicals or degradation by-products which can interact with intermediate chemical species involved in the matrix degradation. They can also be degraded and lead to the formation of supplementary degradation by-products, which can interact with the matrix degradation processes. Moreover, whether fillers are still inert or not during the matrix degradation, this matrix degradation can induce a modification of the fillermatrix interaction: this may have consequences in the reinforcement efficiency of the filler, and therefore be involved in the consequences of the degradation in the overall properties of the composite. 
Very few studies were devoted to the irradiation effect on silica filled rubbers, and they mainly focused on PDMS filled silica systems $[8,9,10,11,12]$. To our knowledge no study concerns the ageing of nanoscopic silica filled (EPDM). However, EPDM is often preferred to silicone because of its excellent capability in electric insulation. When introducing silica in EPDM, the created filler-matrix interactions are very different from those found in silica filled PDMS: there are not strong hydrogen bonds between silica and the matrix. Moreover, in silica/PDMS system, it was shown that covalent bonds are formed at the interface during irradiation [8]. Therefore, the chemistry of the system as well as the initial polymer-filler interaction (van der Waals interaction) being very different in silica-filled EPDM, the consequences of ageing under irradiation could be very different from those found with silica filled PDMS systems. This motivates the present study. In order to understand the role of the semi-crystalline phase in the polymer matrix, the materials after irradiation at room temperature are studied both in the rubbery state (i.e. at $80^{\circ} \mathrm{C}$ ) and in the semi-crystalline state (at room temperature). In most applications, these materials are formulated with a specific coupling agent, such a as bifunctionnal organosilane, which promotes the formation of covalent bonds at the filler matrix interface. For this reason, we also present results obtained with a formulation containing this treatment.

\section{Experimental}

\subsection{Materials}

EPDM elastomer (Nordel IP NDR 3722 P from Dow Chemical Company) is made of 70\% ethylene, $29.5 \%$ propylene and $0.5 \%$ ethylene norbornene (ENB) and the crosslinking agent is dicumyl peroxide (Perkadox BC-FF from Akzo Nobel). EPDM is reinforced with silica ULTRASIL VN3 supplied by Degussa. The filler is highly dispersible silica with a specific surface of $175 \mathrm{~m}^{2} / \mathrm{g}$, the estimated size of a primary particle is c.a. $15 \mathrm{~nm}$. The filler ratio in 
the studied materials is constant and equal to $50 \mathrm{phr}$ (50 weight ratios for 100 weight ratios of EPDM, this corresponds to a weight fraction of $33 \%$, and a volume fraction of $17 \%$ ). The surface treatment chosen to improve the filler-matrix interactions is a vinyltrimethoxysilane Z6300 supplied by Dow Corning. It is made of a reactive foot with three ethoxy groups, which react with the silanol of the silica surface, and an alkyl chains with a vinyl function, which can react with the matrix during crosslinking [13]. Following the procedure of Ramier et al [14], the optimal quantity of surface treatment, to effectively cover this type of silica surface is estimated to $3 \mathrm{phr}$. The so called E-SiU material contains untreated fillers, conversely to the E-SiT material, which contains treated fillers. The samples are processed as follows $[1,15]$ : (i) mixing 2 min of the matrix in an internal mixer, (ii) introduction of the fillers (for treated fillers, the organosilane molecules are introduced with $2 / 3$ of the silica, and then the rest of filler is introduced) and mixing for $5 \mathrm{~min}$, (iii) introduction of $3 \mathrm{phr}$ of peroxide and mixing for $10 \mathrm{~min}$, at $80^{\circ} \mathrm{C}$, (iv) mixing in an external mixer (cylinders) for 10 min at $80^{\circ} \mathrm{C}$, (v) pressing the compound as 1 -mm-thick films at $170{ }^{\circ} \mathrm{C}$ (crosslinking step).We used the common industrial method which consists in measuring with a MONSANTO rheometer the curing time needed to obtain $98 \%$ of the maximum torque extrapolated at infinite cure time $\left(t_{98}\right.$ at $\left.170^{\circ} \mathrm{C}\right)$. Thus the vulcanisation at $170^{\circ} \mathrm{C}$ is stopped after 10 minutes for the unfilled EPDM and after 5 minutes for silica filled EPDM. It was checked by Transmission (JEOL 200CX, on samples obtained from cryo-ultra microtomy) and by Scanning Electron Microscopy performed with an ESEM equipped with a Field Ion Beam (SEM-FIB Nvision40 Zeiss) the good silica dispersion within the polymer matrix (expected for such classical material processing and silica fillers), whether the silica fillers were treated or not. As an example, figure 1 presents a nice SEM-FIB image of E-SiU sample: prior to observation, the sample was gold coated. Then an excavation was performed followed by the 
creation by the FIB of a perfectly flat surface in the sample thickness direction. This surface was then observed in SE mode using an 750V accelerating voltage, and an InLens detector.

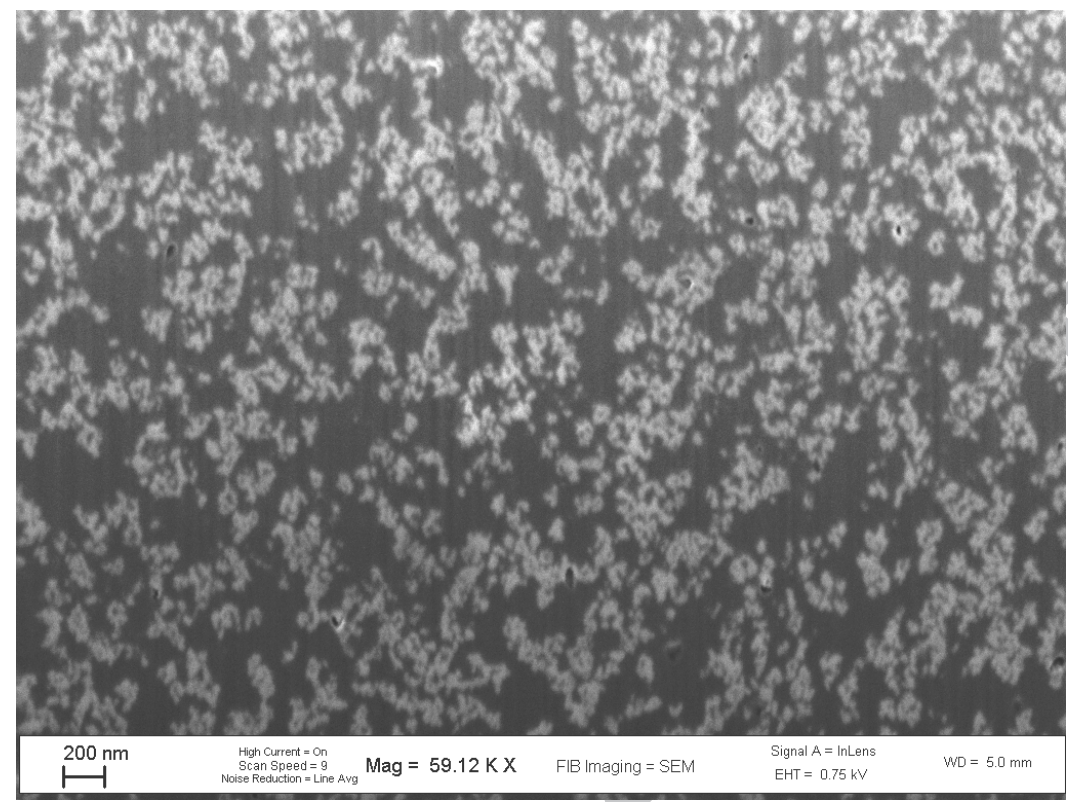

Figure 1: SEM image of a FIB prepared surface of E-SiU sample

The crystallization temperature domain of our EPDM is large [2]: from about $-50^{\circ} \mathrm{C}$ up to $60^{\circ} \mathrm{C}$. A thermal treatment was applied to all samples to obtain a stable crystallinity ratio around $22^{\circ} \mathrm{C}$, in particular during the ageing in the pool at $18^{\circ} \mathrm{C}$, and the post-irradiation at $22^{\circ} \mathrm{C}$ : (i) A heating ramp up to $80^{\circ} \mathrm{C}$ to erase the previous thermal history, (ii) then a rapid cooling down to the optimal crystallization temperature $22^{\circ} \mathrm{C}$ and storage during $12 \mathrm{~h}$ at this temperature (iii) and then a heating ramp of $1^{\circ} \mathrm{C} / \mathrm{min}$ up to $38^{\circ} \mathrm{C}$, the temperature at which the samples are maintained during $6 \mathrm{~h}$. Then the samples are cooled down to $22^{\circ} \mathrm{C}$ and stored at this same temperature. This treatment enables to get a unique well defined melting peak for unfilled EPDM materials and a double peak for silica filled EPDM. Thus these materials have one or two crystallite populations with melting temperatures above $22^{\circ} \mathrm{C}$. 


\subsection{Ageing conditions}

E-CR, E-SiU and E-SiT samples (for unfilled EPDM, and EPDM filled with untreated and treated silica respectively) are exposed to $\gamma$-radiation of a ${ }^{60} \mathrm{CoO}$ source at a dose rate of 1 $\mathrm{kGy} / \mathrm{h}$ in an oxygen atmosphere for doses 50, 165, 300, $510 \mathrm{kGy}$ (Arc Nucleart - Grenoble France): the water temperature of the pool, where exposures are performed, is about $18^{\circ} \mathrm{C}$. Afterwards, the samples are stored under vacuum at about $22^{\circ} \mathrm{C}$. The samples will be named hereafter E-CR-XXX, E-SiU-XXX and E-SiT-XXX with XXX the irradiation dose.

IR spectroscopy showed for all the irradiated samples an increase in absorbance in the hydroxyl absorption region (3800-3000 $\left.\mathrm{cm}^{-1}\right)$ and in the carbonyl region $\left(1600-1800 \mathrm{~cm}^{-1}\right)$ [3] Because of the filler presence, it is not possible to quantify these products by ATR and thus to compare the oxidation level of the different elastomers. Nevertheless, oxidation (carbonyl) profiles were evaluated from IR-microspectroscopy using a Continuum microscope coupled to a Nexus Nicolet optical bench $\left(32\right.$ scans, resolution of $4 \mathrm{~cm}^{-1}$, analysis conducted at the CNEP - Clermont Ferrand, France). A slice of sample of about $40 \mu \mathrm{m}$ was cut by cryomicrotom in the thickness direction. Variations in absorbance at $1713 \mathrm{~cm}^{-1}$ were measured on this slice every $50 \mu \mathrm{m}$. Profiles for E-CR-510 and E-SiU-510, were found nearly flat, indicating that the oxidation processes can be considered homogeneous within the thickness.

\subsection{Instruments}

\subsubsection{Swelling measurements}

\subsubsection{Swelling in xylene}

Samples with an initial mass $\mathrm{M}_{\mathrm{i}}$ are introduced in xylene for 8 days to achieve the swelling equilibrium; then the materials with a swelled mass $M_{s}$ are dried under vacuum at $60^{\circ} \mathrm{C}$ 
during 1 day and finally weighted to obtain the dried mass $M_{d}$. In the case of the composites, TGA (TGA F3 apparatus from Netzch) enables to estimate the filler weight ratio $\varepsilon_{\mathrm{i}}$ in the initial sample and the filler weight ratio $\varepsilon_{\mathrm{d}}$ in the dried sample after swelling. Therefore, the swelling ratio $\mathrm{Q}$ and the polymer soluble fraction $\mathrm{F}_{\mathrm{p}}(\%)$ can be evaluated from:

$$
\begin{gathered}
Q=1+\frac{\rho_{\text {polymer }}}{\rho_{\text {xylene }}} \frac{M_{s}-M_{d}}{M_{d}\left(1-\varepsilon_{d}\right)} \\
F_{p}=\frac{\left(1-\varepsilon_{i}\right) M_{i}-\left(1-\varepsilon_{d}\right) M_{d}}{\left(1-\varepsilon_{i}\right) M_{i}}
\end{gathered}
$$

At low dose, given the low sol fraction measured for E-SiU and E-SiT materials, the difference found between $\varepsilon_{\mathrm{d}}$ and $\varepsilon_{\mathrm{i}}$ is within the experimental uncertainties. However, for high irradiation dose, actually for total sol fractions above $20 \%$, it is found that $\varepsilon_{\mathrm{d}}$ is clearly lower than $\varepsilon_{i}$, meaning that the sol fractions contain a significant amount of fillers.

\subsubsection{Water uptake}

Because of the presence of silanol on its surface and of its large specific surface, silica can absorb a significant amount of water. To measure it, the samples, cut as identical parallelepipeds to offer a constant surface to the water, are firstly dried under vacuum for $24 \mathrm{~h}$ at $100^{\circ} \mathrm{C}$ to remove the maximum amount of water on the silica surface. After weighting dried samples $\left(\mathbf{M}_{\text {dried }}\right)$, they are put in distilled water at room temperature for one month and then weighted again $\left(\mathrm{M}_{\text {swollen }}\right)$. The water uptake $\mathrm{S}_{\mathrm{w}}$ (expressed in $\%$ ) is then calculated from:

$$
S_{w}=\frac{M_{\text {swollen }}-M_{\text {dried }}}{M_{\text {dried }}} \times 100
$$

\subsubsection{Tensile tests}

Experiments (on an MTS device equipped with a temperature controlled chamber) are conducted at $80^{\circ} \mathrm{C}$ and at $25^{\circ} \mathrm{C}$ with a true strain rate $0.01 \mathrm{~s}^{-1}$. An image processing 
acquisition system (Apollor VideoTraction System) is used to obtain the true stress - true strain curve. The samples are dumbbell-shaped with dimensions $20 \times 4 \times 1 \mathrm{~mm}^{3}$. For one type of samples, three specimens are tested; on figures only one test is reported, but the average stresses and strains at break on the three specimens are given in a separated table 2. Note that the rupture has not been reached for the E-SiU samples. Besides, the elastic modulus $\mathrm{E}$ is calculated as the slope of the linear initial portion of the curve. Tensile test cycles are also performed at $80^{\circ} \mathrm{C}$. Sample is stretched up to a 0.2 true strain, then relaxed during 5 minutes; then, it is stretched again up to a 0.4 true strain. This experience is repeated with a 0.2 true strain increment until the sample rupture.

\section{Results and discussions}

\subsection{Preliminary characterization of the studied materials}

As reported in figure 2, the swelling ratio Q of E-SiU is higher (4.2) than the matrix one (3.7). As suggested in the experimental part, the polymer matrix of the composite may be slightly less crosslinked than the unfilled EPDM because of the choice of the curing time. This is in agreement with the sol fraction $F_{p}$ values (cf. Table 1): E-SiU contains a soluble fraction of about $3.2 \%$, conversely to the unfilled sample, although this result must be considered with caution because of the experimental uncertainties. Note that this soluble fraction could also be due to occluded polymer in the complex filler structure. The elastic modulus at $80^{\circ} \mathrm{C}$ of E-SiU (Table 1) is about 4.5 times higher than the modulus of E-CR. This is much higher than the reinforcement predicted by the Christensen and Lo model [17]. This model has shown its validity for micron size filler [15] and predicts a reinforcement of a factor 1.6 for $20 \%$ vol. of

filler. This discrepancy between theory and experiments is generally explained by the formation of a strong filler network [7]. 


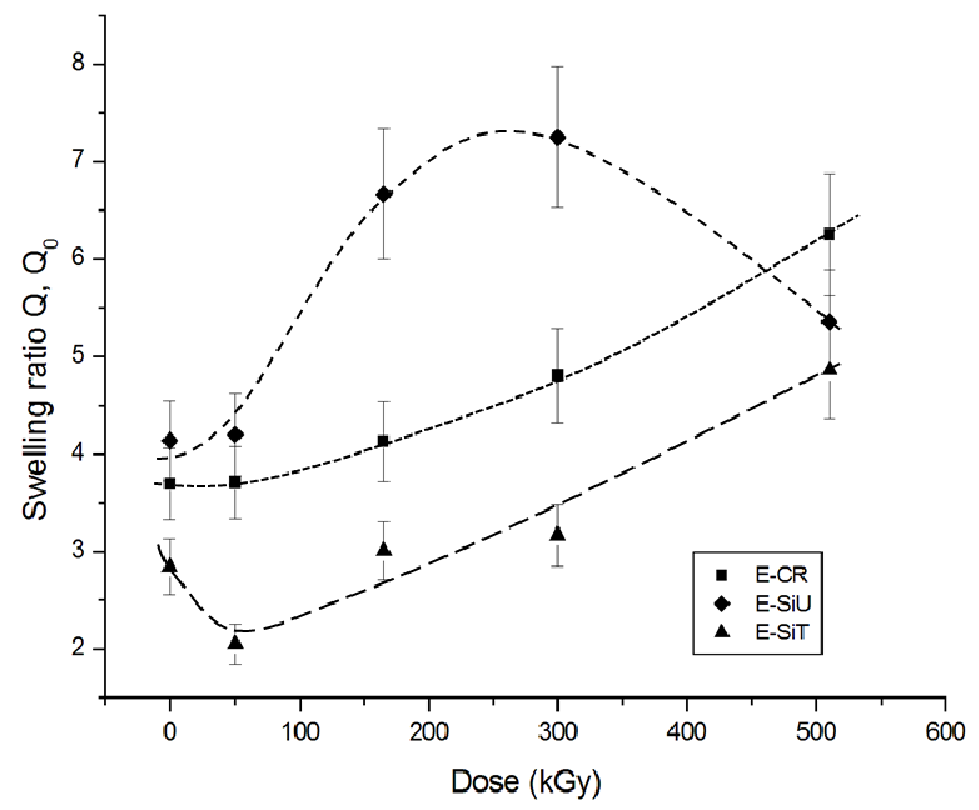

Figure 2: Swelling ratio $Q$, as a function of radiation dose, dashed lines are guide for the

The efficiency of the silica surface treatment in E-SiT is first evidenced by the water uptake measurements (cf. Figure 3): $\mathrm{S}_{\mathrm{w}}$ is more important for E-SiU than for E-SiT. Nevertheless, the soluble fraction of E-SiT is higher than the one found for E-SiU. Thus, the E-SiT polymer phase is certainly slightly less crosslinked than that of E-SiU. The reasonable explanation is that a part of the peroxide has been used in the filler/matrix coupling reactions. Despite this, the swelling ratio of E-SiT is smaller (2.8) than the one of E-CR. This is not surprising: indeed, in the case of nanocomposites such as the studied materials, in which nanoscopic fillers likely form a percolating reinforcing structure [7], filler-matrix covalent bonds become important in the material response at larger strains, in particular for strain level such as that involved in the swelling measurements, or for strains at which hardening appears in stressstrain curve, that is when the filler structure is stretched (cf. Figure $4 a$ and $4 b$ ). 
Conversely, at small deformations (i.e. in the deformation range of the shear modulus measurement), the nature of the polymer-filler bonds, the fact that they are covalent or physical, is not a key parameter, presumably because they are in any case strong enough to transfer the stress at the filler-matrix interface. Thus, the elastic modulus at $80^{\circ} \mathrm{C}$ of $\mathrm{E}-\mathrm{SiT}$ is slightly smaller than the one of E-SiU (cf. Table1). This lower modulus can be attributed to the slightly less crosslinked matrix previously suggested, or to a less reinforcing filler structure [18]: the filler treatment may lead to a decrease in the filler-filler interactions by promoting the filler-matrix ones, leading to a less reinforcing filler.

The rupture behaviour cannot be discussed for the E-SiU samples, since they systematically break in the clamps. The authors have no explanation for this peculiar behaviour. However, it can be observed that E-SiT breaks earlier and not in the clamps. The silane treatment seemingly leads to a more brittle behaviour of this material, as already observed in the study of treated and untreated ATH filled EPDM [15]. This might be attributed to the absence of decohesion mechanism which might delay sample rupture by decreasing the local matrix stretching.

\subsection{Degradation kinetic - Consequences on mechanical properties at $80^{\circ} \mathrm{C}$}

$\underline{\boldsymbol{E}-\boldsymbol{C R} \text { material: }}$ The consequences of irradiation on unfilled E-CR are already reported in reference 1 . At the beginning of irradiation (below $50 \mathrm{kGy}$ ), no change of the swelling ratio (cf. Figure 2), a slight increase in the soluble fraction (cf. Table 1) and in the elastic modulus measured at $80^{\circ} \mathrm{C}$, i.e. above the melting temperature, (cf. Table 1) suggests that this material is submitted to concomitant crosslinking / chain scissions processes. Note that this interpretation is also supported by the evolution of initially uncrosslinked EPDM subjected to gamma irradiation [1]). Then at higher irradiation dose, the increases in the swelling ratio and 
in the soluble fraction indicate that chain scissions become the preponderant occurring phenomenon. The sol fraction evolution can be correctly described using the Charlesby approach which enables to calculate the chain scission kinetic. The consequences of the degradation process on the mechanical properties are recalled on figure 4 and tables 1 and 2: the modulus at $80^{\circ} \mathrm{C}$ decreases as well as the stress level of the tensile curves, and the ultimate properties deteriorates.

\begin{tabular}{|c|c|c|c|c|c|c|}
\hline $\begin{array}{c}\text { Dose } \\
(\mathrm{kGy})\end{array}$ & \multicolumn{2}{|c|}{ E-CR } & \multicolumn{2}{c|}{ E-SiU } & \multicolumn{2}{c|}{ E-SiT } \\
\hline & $\mathrm{F}_{\mathrm{p}}(\%)$ & $\begin{array}{c}\mathrm{E} \text { at } 80^{\circ} \mathrm{C} \\
(\mathrm{MPa})\end{array}$ & $\mathrm{F}_{\mathrm{p}}(\%)$ & $\begin{array}{c}\mathrm{E} \text { at } 80^{\circ} \mathrm{C} \\
(\mathrm{MPa})\end{array}$ & $\mathrm{F}_{\mathrm{p}}(\%)$ & $\begin{array}{c}\mathrm{E} \text { at } 80^{\circ} \mathrm{C} \\
(\mathrm{MPa})\end{array}$ \\
\hline 0 & $0 \pm 3$ & $2.9 \pm 0.3$ & $3.2 \pm 3$ & $13.8 \pm 1.4$ & $5.2 \pm 3$ & $12.7 \pm 1.3$ \\
\hline 50 & $2.9 \pm 3$ & $3.1 \pm 0.3$ & $3.6 \pm 3$ & $13.5 \pm 1.4$ & $4.3 \pm 3$ & $13.2 \pm 1.3$ \\
\hline 165 & $5.7 \pm 3$ & $2.6 \pm 0.3$ & $25.3 \pm 3$ & $10.8 \pm 1.1$ & $6.3 \pm 3$ & $10.1 \pm 1$ \\
\hline 300 & $8.8 \pm 3$ & $2.1 \pm 0.2$ & $33.8 \pm 3$ & $9.6 \pm 1$ & $10 \pm 3$ & $9.7 \pm 1$ \\
\hline 510 & $20.6 \pm 3$ & $1.2 \pm 0.1$ & $35.6 \pm 3$ & $8.5 \pm 0.9$ & $33.3 \pm 3$ & $5.3 \pm 0.5$ \\
\hline
\end{tabular}

Table 1: Soluble fraction $F_{p}(\%)$, elastic moduli $\mathrm{E}$ at $80^{\circ} \mathrm{C}(\mathrm{MPa})$ of the different materials

$\underline{\text { E-SiU material: }}$ Between $0 \mathrm{kGy}$ and $50 \mathrm{kGy}, \mathrm{E}-\mathrm{SiU}$ does not show any significant evolution of the swelling ratio (cf. Figure 2), of the sol fraction $\left(\mathrm{F}_{\mathrm{p}}\right)$ and of the elastic modulus at $80^{\circ} \mathrm{C}$ (cf. Table 1). Thus, at $50 \mathrm{kGy}$, there is not a modulus maximum like in the case of the E-CR. Given the assumed crosslink density lower in this material than in E-CR, and assuming the occurrence of a crosslinking process induced by radiation (such as the one suggested by the slight modulus and sol fraction evolutions in the case of E-CR), it can be assumed that the matrix in the filled sample has also been submitted to the same competing mechanisms of crosslinking and scissions. Within this assumption, the absence of modulus maximum at 50 kGy might be due either to its shift at a lower irradiation dose (experiments at lower radiation dose could then confirm it), or to the fact that the crosslinking process never counterbalances the chain sicssions. 


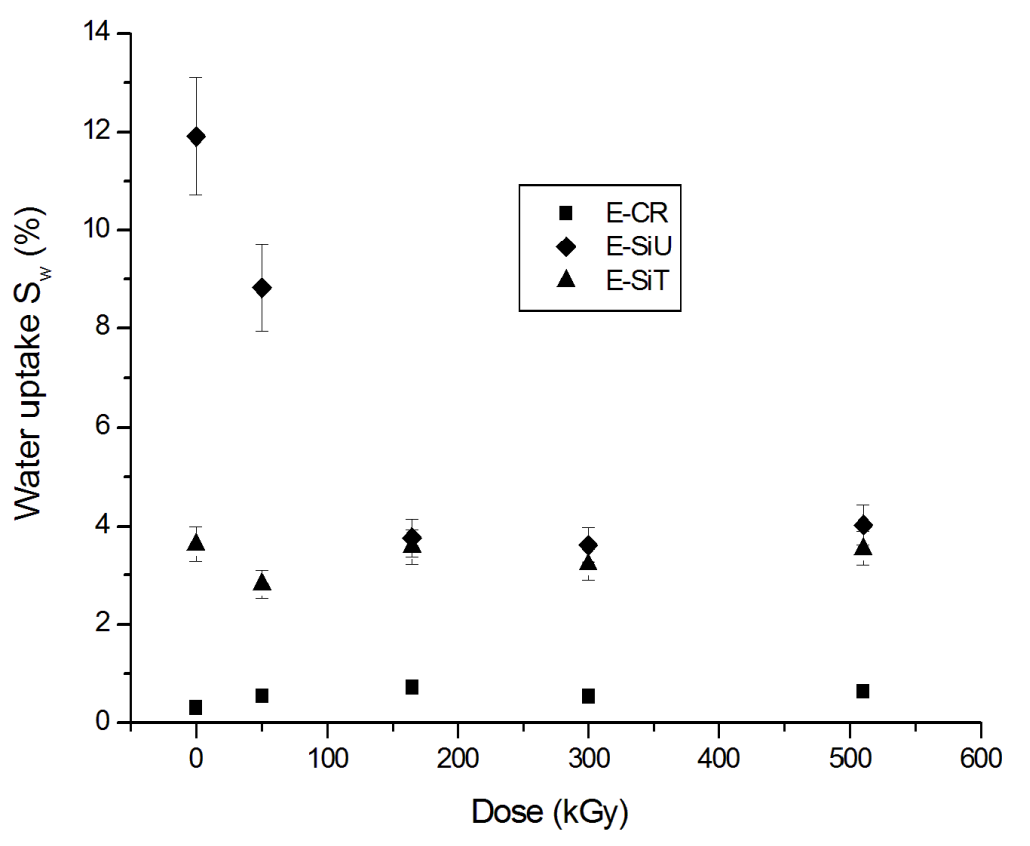

Figure 3: Water uptake $S_{w}$ as a function of radiation dose

At irradiation doses above $50 \mathrm{kGy}$ and up to $300 \mathrm{kGy}$, the swelling ratio rapidly increases (cf. Figure 1), as well as the polymer soluble fraction $\mathrm{F}_{\mathrm{p}}$ (cf. Table 1). Chain scissions take place, but as indicated by the larger extracted polymer ratio $\mathrm{F}_{\mathrm{p}}$ of the filled rubber (at $165 \mathrm{kGy}, 25 \%$ against $6 \%$ for E-CR), this phenomenon is much more important than in the case of unfilled material. The same amount of sol fraction is found in E-SiU at $165 \mathrm{kGy}$ as in E-CR material at $510 \mathrm{kGy}$. This sol fraction variation is correlated with the decreases in the elastic modulus at $80^{\circ} \mathrm{C}$ (cf. Table 1) and in the stress levels measured in tensile test at $80^{\circ} \mathrm{C}$ (cf. Figure 4). In addition, a modification of the silica surface is evidenced by the water uptake measurements, which show a strong decrease of $S_{w}$ between 0 and $165 \mathrm{kGy}$ (cf. Figure 3), indicating that the silica surface becomes less hydrophilic, i.e. that the silanol initially on its surface are degraded. These results strongly suggest that the fillers promote supplementary reactions in 
the filler vicinity. Indeed, it has been reported that the irradiation of silica involves the formation of numerous radicals in the bulk $[19,8,10]$. They may tend to recombine or diffuse to the surface, making the surface reactive, and accelerating degradation reactions, in the filler-surface vicinity.

At doses above $165 \mathrm{kGy}$, both modulus and soluble fraction tend to stabilize. Moreover, the stability of $S_{\mathrm{w}}$ suggests that the silica surface hydrophilicity is not significantly modified anymore. However, the swelling ratio goes through a maximum at $300 \mathrm{kGy}$ to decrease at 510 kGy. This indicates that an additional mechanism of crosslinking occurs and counterbalances the chain scission process. Such phenomenon was not observed in the case of polymer E-CR. As shown in the material stress-strain curves of E-SiU at 510kGy (cf. figure 4), the formation of these supplementary crosslinks leads to an increase in hardening. Thus, there are two sequences in the modification of the silica surface under irradiation: first, it is made more hydrophobic, and then it reacts with the polymer matrix in its vicinity to form covalent bonds. To confirm the strengthening of the filler-matrix interaction, non-irradiated and irradiated E$\mathrm{SiU}$ samples have been subjected to cycle tensile tests at $80^{\circ} \mathrm{C}$ (cf. Insert in figure 5). The area delimited by two successive tests, which is significant of the energy damage, is plotted as function of the maximal stress reached for each cycle in figure $5 \mathrm{~b}$ ). Unexpectedly, Irradiation does not strongly modify the cycle area versus stress curve. This means that the bonds formed during irradiation are not numerous enough to lead to a significant modification of the damage behaviour. 
a)
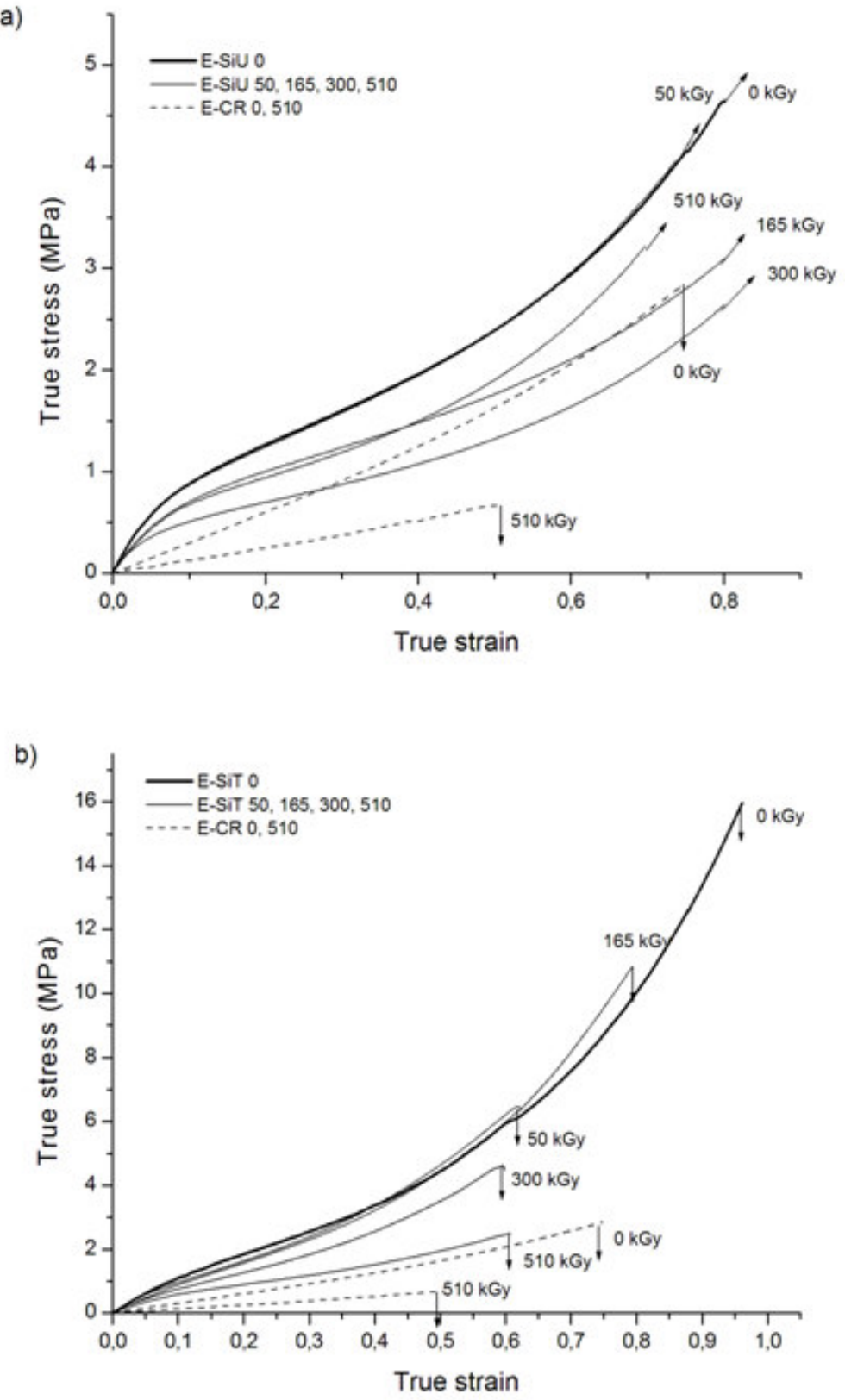

Figure 4: Large deformation behavior at $80^{\circ} \mathrm{C}$ of a) E-SiU (no rupture is observed) and of b)

$$
\text { E-SiT (cf. table 2) }
$$

$\underline{\text { E-SiT material: }}$ In this case, between 0 and $50 \mathrm{kGy}$, a slight crosslinking phenomenon is noticeable as evidenced by a modulus increase and the swelling ratio decrease. This can be due to some additional filler-matrix coupling reactions formed by some residual silane 
treatment, which has not been covalently bonded to the matrix. This can also be due to crosslinking reactions in the matrix provided by some residual peroxide, since it has been shown that the polymer phase of this material is slightly less crosslinked. As shown in figure 3 , the consequences of this crosslinking on the stress-strain curves are a more important hardening and an earlier rupture in addition to an increase in modulus.

Above $50 \mathrm{kGy}$ and up to $300 \mathrm{kGy}$, the swelling ratio (cf. Figure 2) and the soluble fraction (cf. Table 1) also increase with the radiation dose, but these increases are much less important than for E-SiU; actually they are comparable to those measured for E-CR. Thus, the polymer degradation is seemingly similar to that of E-CR. There is no indication of a more rapid scission mechanism such as that found in the case of E-SiU. However one can note between $300 \mathrm{kGy}$ and $500 \mathrm{kGy}$ that the swelling ratio and the sol fraction rapidly increases and reaches the values found for E-SiU. Thus, the fast scission mechanism seems to be delayed by the silane treatment and to occur at larger radiation dose. Such interpretation is supported by the evolution of the mechanical properties with the radiation dose. The stress-strain curves show a delayed decrease of the stress level at a given strain when compared with the stress-strain curves of E-SiU: the decrease becomes significantly visible from $300 \mathrm{kGy}$ and it accelerates between 300Gy and $500 \mathrm{kGy}$. Eventually, after ageing at 500kGy, the materials with treated and untreated silica have very similar stress-strain curves at $80^{\circ} \mathrm{C}$; moreover, given their same swelling ratio, it can be deduced that both materials have about the same number of covalent bonds at the filler-matrix interface. E-SiT samples have also been subjected to cyclic tensile tests at $80^{\circ} \mathrm{C}$ (cf. Figure 5). The non irradiated E-SiT shows an increase in the energy for a higher stress than E-SiU: this evidences the strongest filler-matrix interface in E-SiT, which breaks at higher stress than E-SIU. The cycle performed on E-SIT-510 leads to an energy curve similar to the one of E-SIU510, with an increase in energy which begins at the same stress as E-SiU-510. This confirms that a large number of initially mechanically active 
covalent bonds at the filler-matrix interface have been deactivated by chain scissions in the interface vicinity.

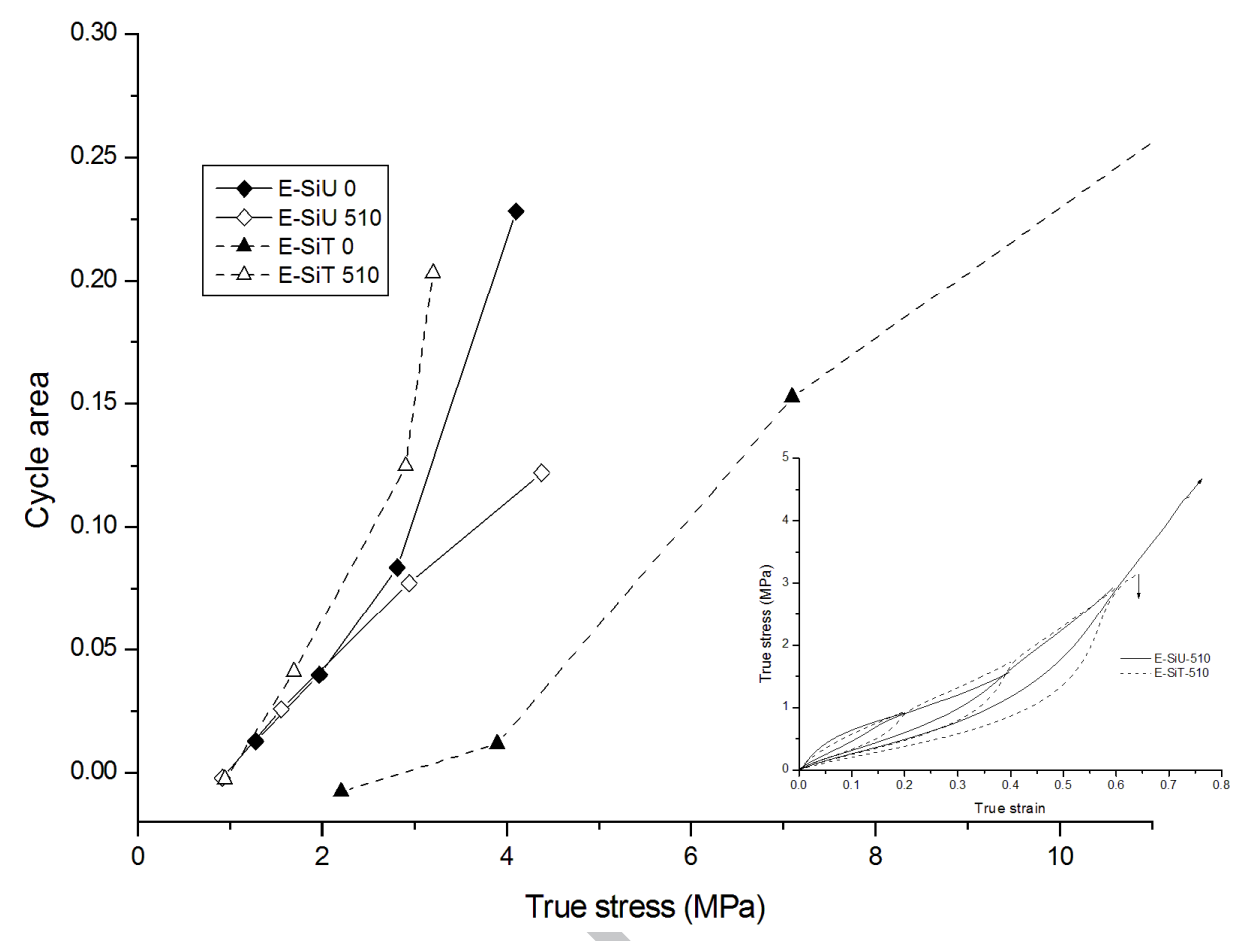

Figure 5: Evolution of the cycle area versus true stress for E-SiU and E-SiT at $0 k G y$ and at $510 \mathrm{kGy}$; Insert: Cycles at $80^{\circ} \mathrm{C}$ for E-SiU-510 and E-SiT-510

In addition, the modulus value lower for E-SiT than for E-SiU might suggest that, especially at $510 \mathrm{kGy}$, all things equal, i.e. the matrix crosslink density, and the filler-matrix interaction, the filler structure in E-SiT is actually less reinforcing than the one in E-SIU; this would be not surprising since the use of a filler treatment is known to impact the filler network by reducing the filler-filler interaction [13].

\subsection{Consequences on mechanical properties at $25^{\circ} \mathrm{C}$}


As reported in [2] E-CR presents a lamellar microstructure in the undeformed state which is not strongly modified by irradiation (only a very limited chemi-cristallisation process has been evidenced). The cristallinity ratios of E-SiU, and E-SiT deduced from DSC measurements (on a Perkin Elmer Pyris Diamond) prior and after irradiation, as well as their melting temperature are not significantly different from those found for E-CR. This indicates that, irradiation has the same negligible impact on the polymer crystalline microstructure, with or without the filler presence. This was expected since the introduction of silica does not either significantly modify the polymer cristallinity in the non irradiated E-SiU and E-SiT.

\begin{tabular}{|c|c|c|c|c|}
\hline \multirow{2}{*}{ Samples } & \multicolumn{2}{|c|}{ At $80^{\circ} \mathrm{C}$} & \multicolumn{2}{c|}{ At $25^{\circ} \mathrm{C}$} \\
\cline { 2 - 5 } & Strain at break & $\begin{array}{c}\text { Stress at break } \\
(\mathrm{MPa})\end{array}$ & Strain at break & $\begin{array}{c}\text { Stress at break } \\
(\mathrm{MPa})\end{array}$ \\
\hline E-CR-0 & $0.8 \pm 0.1$ & $2.8 \pm 0.3$ & $1.6 \pm 0.2$ & $16.8 \pm 4$ \\
\hline E-CR-510 & $0.5 \pm 0.1$ & $0.7 \pm 0.1$ & $1.2 \pm 0.1$ & $7.2 \pm 1.3$ \\
\hline E-SiT-0 & $1 \pm 0.1$ & $16 \pm 1.6$ & $1.4 \pm 0.1$ & $60.4 \pm 18$ \\
\hline E-SiT-50 & $0.6 \pm 0.1$ & $6.2 \pm 1$ & $1.3 \pm 0.1$ & $47 \pm 12$ \\
\hline E-SiT-165 & $0.8 \pm 0.1$ & $10.6 \pm 2$ & $1.4 \pm 0.2$ & $47 \pm 15$ \\
\hline E-SiT-300 & $0.6 \pm 0.1$ & $4.6 \pm 0.5$ & $1.2 \pm 0.2$ & $32 \pm 11$ \\
\hline E-SiT-510 & $0.6 \pm 0.1$ & $2.5 \pm 0.35$ & $1.1 \pm 0.2$ & $21 \pm 6$ \\
\hline
\end{tabular}

Table 2: Average stresses and strains at break for E-SiT and E-CR at $80^{\circ} \mathrm{C}$ and at $25^{\circ} \mathrm{C}$

Figures 6 a), 6 b) and table 2 and 3 present tensile test results at $25^{\circ} \mathrm{C}$ of E-SiU and E-SiT, E$\mathrm{CR}$ and E-CR-510. As shown on these figures, the mechanical properties at $80^{\circ} \mathrm{C}$ and at $25^{\circ} \mathrm{C}$ are very different because of the presence of crystallites at room temperature. E-Si and E-SiT have the same modulus which is, like at $80^{\circ} \mathrm{C}$, much higher than that of the unfilled sample: the slightly higher ratio of the filled sample modulus by the modulus of the unfilled sample (around 6 at $25^{\circ} \mathrm{C}$ against 4.5 at $80^{\circ} \mathrm{C}$ ) suggests that the reinforcement is due to a mixed crystallite silica network. This idea is supported by the size of silica fillers (around $15 \mathrm{~nm}$ ) which is in the same range as the crystallite size. 

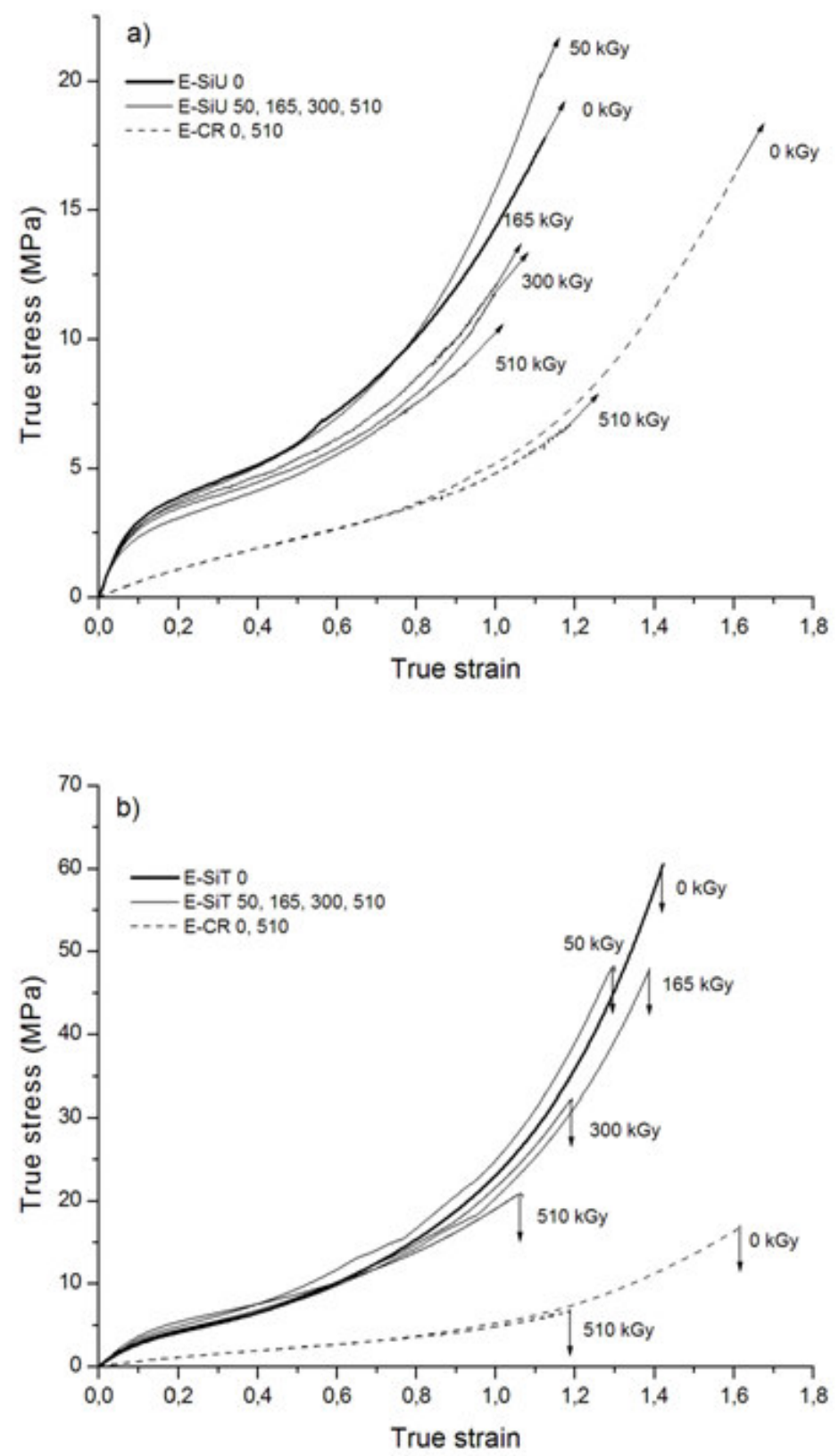

Figure 6: Large deformation behavior at $25^{\circ} \mathrm{C}$ of a) E-SiU (no rupture is observed) and of b)

\section{E-SiT}




\begin{tabular}{|c|c|c|c|}
\hline $\begin{array}{c}\text { Dose } \\
(\mathrm{kGy})\end{array}$ & E-CR & E-SiU & E-SiT \\
\hline 0 & $5.8 \pm 0.6$ & $33.8 \pm 3.4$ & $34.4 \pm 3.4$ \\
\hline 50 & $5.8 \pm 0.6$ & $33.8 \pm 3.4$ & $39 \pm 3.9$ \\
\hline 165 & $5.8 \pm 0.6$ & $40.5 \pm 4.1$ & $39.4 \pm 3.9$ \\
\hline 300 & $6 \pm 0.6$ & $44.7 \pm 4.5$ & $43 \pm 4.3$ \\
\hline 510 & $5.9 \pm 0.6$ & $41.8 \pm 4.2$ & $39.1 \pm 3.9$ \\
\hline
\end{tabular}

Table 3: Elastic moduli E at $25^{\circ} \mathrm{C}(\mathrm{MPa})$ for different materials

The modulus slightly increases in the beginning of irradiation, due to the small chemicrystallisation phenomenon. Thus, like observed in the study of the effect of irradiation on ECR [2], the crystallite presence strongly decreases the impact of the degradation on the mechanical properties in the semi-crystalline state. Such phenomenon has also been highlighted for others semi-crystalline polymers, such as, for instance, polyethylene [20]. This holds true for strain below 0.4 since the tensile curves obtained at the different irradiation doses for E-SiU of for E-SiT are nearly superimposed (Figure 5). At larger strain, the degradation of the amorphous phase, already evidenced at $80^{\circ} \mathrm{C}$, obviously decreases the stress transfer between crystallites during the matrix deformation, leading to a decrease in the hardening phenomenon.

The creation of filler-matrix bonds in the E-SiU samples by high irradiation dose has a limited impact on the hardening process of the corresponding tensile curve at $25^{\circ} \mathrm{C}$. As assumed above, this means that these bonds are in small numbers. Besides, even if E-SiU and E-SiT have similar stress-strain curves at $80^{\circ} \mathrm{C}$, all the E-SiT curves obtained at $25^{\circ} \mathrm{C}$ show a much more important hardening than the tensile curves obtained with the E-SiU samples. Whatever the irradiation dose, the stress level measured for E-SiT is much higher than the one measured with E-SiU (a ratio of about 2 is observed for a true strain equal to 1). Thus, the crystallites presence partly heals the desactivation of the filler-matrix covalent bonds. 


\section{Conclusions}

The incorporation of nanoscopic fillers in EPDM induces the formation of a filler network with a larger reinforcement efficiency than when the fillers are micron size. The materials with treated fillers have an elastic modulus close to the one of EPDM filled with untreated fillers. But in the amorphous state like in the semi-crystalline state, they show more important hardening with a faster rupture. At $25^{\circ} \mathrm{C}$, the reinforcement measured for both materials is higher than the one found at $80^{\circ} \mathrm{C}$, which indicates the formation of a mixed crystallite silica network.

These materials have been irradiated at room temperature:

- Without treatment, the polymer phase degradation is accelerated. Our explanations is the formation of supplementary radicals induced by the silica irradiation. At the highest irradiation dose studied, a particular mechanism can be observed: due to the modification of the silica surface, stronger interactions between filler and matrix are formed.

- The silica treatment enables to delay the degradation acceleration to the highest radiation dose studied. In addition, irradiation, leads to a mechanical deactivation of the initially present covalent bonds at the interface, either by their direct degradation, or by the degradation of the polymer in their vicinity.

- As a consequence, both filled rubbers (with and without silane treatment) have similar mechanical behavior at $80^{\circ} \mathrm{C}$ at $510 \mathrm{kGy}$. At room temperature, i.e. in the semi crystalline state, their properties are mainly controlled by the crystalline microstructure which is not significantly modified by radiation. In addition, at room temperature, conversely to the filler-matrix covalent bonds created by the silane treatment, those created by gamma 
irradiation in the composite with untreated silica have a much lower impact on the mechanical properties.

To conclude, the different experimental results clearly show that the presence of silica fillers as well as their surface treatment influences the impact of irradiation on the mechanical properties of the filled materials. They influence it both chemically, by a modification of the kinetics of the degradation reactions, and physically, through the complex modification by irradiation of the filler-filler and filler-matrix interaction involved in the mechanical properties of the filler network.

\section{Acknowledgments}

It is a pleasure to acknowledge the joint research program "COPOLA" between EDF, NEXANS France, LABORELEC, CEA, INRA and CNRS. We also greatly acknowledge B. Van De Moortele for the SEM-FIB images.

\section{References}

1. Planes E, Chazeau L, Vigier G, Fournier J. Evolution of EPDM networks aged by gamma irradiation - Consequences on the mechanical properties. Polymer 2009; 50: $4028-4038$

2. Planes E, Chazeau L, Vigier G, Chenal JM, Stuhldreier T. Crystalline microstructure and mechanical properties of crosslinked EPDM aged under gamma irradiation. J. Pol. Sci.: Part B: Pol Phys. 2010; 48: 97-105

3. Rivaton A, Cambon S, Gardette JL. Radiochemical ageing of EPDM elastomers. 2. Identification and quantification of chemical changes in EPDM and EPR films 
gamma-irradiated under oxygen atmosphere. Nucl. Instr. and Meth. in Phys. Res. B 2005; 227: 343-356

4. Rivaton A, Cambon S, Gardette JL. Radiochemical ageing of EPDM elastomers. 3. Mechanism of radiooxidation Nucl. Instr. and Meth. in Phys. Res. B 2005; 227: 357368

5. Richaud E, Colin X, Fayolle B , Audouin L, Verdu J. International Journal of Chemical Kinetics, 2008 ; 40 : 769-777

6. Khelidj N, Colin X, Audouin L, Verdu J, Monchy-Leroy C, Prunier V. Polymer Degradation and Stability, 2006; 91: 1593-1597

7. Chazeau L, Gauthier C, Vigier G, Cavaille J.Y. Handbook of "organic-inorganic hybrid materials and nanocomposites, Pt2" Dr. H.S. Nalwa ed., American Scientific Publishers, 2004

8. Stevenson I, David L, Gauthier C, Arambourg L, Davenas J, Vigier G. Influence of $\mathrm{SiO}_{2}$ fillers on the irradiation ageing of silicone rubbers. Polymer 2001; 42: 9287-9292

9. Chien A, Maxwell R, Chambers D, Balazs B, Lemay J. Characterization of radiationinduced aging in silica-reinforced polysiloxane composites. Rad. Phys. and Chem. 2000; 59; 493-500

10. Patel M, Morrell PA, Murphy JJ, Skinner A, Maxwell RS, Gamma radiation induced effects on Silica and on silica-polymer interfacial interactions in filled polysiloxane Rubber. Pol. Deg. and Stab. 2006; 91: 406-413

11. Maxwell RS and Balazs B, Residual dipolar coupling for the assessment of cross-link density changes in $\gamma$-irradiated silica-PDMS composite materials. J Chem. Phys. 2002; 116(23): 10492-10502 
12. Maxwell RS, Cohenour R, Sung W, Solyom D, Patel M. The Effects of gammaradiation on the thermal, mechanical, and segmental dynamics of a silica filled, room temperature vulcanized polysiloxane rubber. Pol. Deg. and Stab. 2003; 80: 443-450

13. Pal PK and DE SK. Studies on peroxide vulcanization of silica filled EPDM rubber in presence of vinyl silane coupling agent. Polymer. 1984; 25: 855-862

14. Ramier J, Chazeau L, Gauthier C, Guy L, Bouchereau MN. Grafting of silica during the processing of silica-filled SBR : comparison between length and content of the silane. J. Pol. Sci.: Part B: Pol. Phys. 2006; 44: 143-152

15. Planes E, Chazeau L, Vigier G, Fournier J, Stevenson-Royaud I. Influence of fillers on mechanical properties of ATH filled EPDM during ageing by gamma irradiation. Accepted in Polymer Degradation and Stability

16. Bandrup J, Immergut E, Grulke E. Polymer handbook. Editors New-York: Wiley Interscience Publication; 1999

17. Christensen RM and Lo KH. Solutions for effective shear properties in three phase sphere and cylinder models, Journal of the Mechanics and Physics of Solids, 1979; 27:315-330

18. Ramier J, Gauthier C, Chazeau L, Stelandre L, Guy L. Payne effect in silica-filled styrene-butadiene rubber. Influence of surface treatment. J. Appl. Pol. Sci.: Part B: Pol. Phys. 2007; 45: 286-298

19. Cataldo F, Capitani D, Proietti N, Ragni P. $\gamma$ radiolyzed amorphous silica: A study with ${ }^{29}$ Si CP-MAS NMR spectroscopy. Rad. Phys. and Chem. 2008; 77: 267-272

20. Aslanian VM, Vardanian VL, Avertisian MH, Felekian SS, Ayvasian SR. Effect of radiation on the crystallinity of low-density polyethylene. Polymer 1987; 28:755-757 